\title{
A CONSTITUCIONALIZAÇÃO DO DIREITO CIVIL E SEUS REFLEXOS NA RESPONSABILIDADE CIVIL
}

\author{
Bernardo Gomes Barbosa Nogueira ${ }^{1}$ \\ Helimar Fialho Guimarães ${ }^{2}$
}

\begin{abstract}
RESUMO
O presente artigo objetiva analisar os reflexos da Constitucionalização do Direito Civil no campo do instituto da Responsabilidade Civil. Desta feita, busca-se demonstrar a importância de todos aqueles que lidam com o Direito, em especial no que tange à reparação de danos, assegurarem a aplicação das normas privadas com respeito ao princípio da dignidade da pessoa humana e demais garantias constitucionais.
\end{abstract} Fundamentais.

Palavras-chave: Constitucionalização. Responsabilidade Civil. Direitos

\section{THE CONSTITUTIONALIZATION OF CIVIL LAW AND ITS REFLECTIONS ON CIVIL RESPONSIBILITY}

\begin{abstract}
This article aims to analyze the impacts of Constitutionalisation field of Civil Law from the Institute of Civil Responsibility. This time, we seek to demonstrate the importance of all those who deal with the law, especially in regard to compensation for damage, ensure the implementation of private standards with respect to the principle of human dignity and other constitutional guarantees.
\end{abstract}

Keywords: Constitutionalization. Civil Responsibility. Fundamental rights.

\footnotetext{
${ }^{1}$ Mestre em Direito pela Faculdade de Direito da Universidade de Coimbra, professor do curso de Direito, FADIP, UNIPAC/ITABIRITO e NEWTON PAIVA. E-mail: bernardogbn@ yahoo.com.br

${ }^{2}$ Acadêmica do $9^{\circ}$ período do Curso de Graduação em Direito da Faculdade Dinâmica do Vale do Piranga - FADIP. E-mail: helimarfg@ hotmail.com
} 


\section{INTRODUÇÃO}

A revolução industrial, a revolução feminista, as catástrofes humanas ocorridas sobremaneira na segunda grande guerra, a falácia do abstrato e racional da modernidade em meio a uma ordem jurídica que preceituava valores abstratos e se fiava na propriedade como esteio central, foram algumas das inúmeras causas que concorreram para a decadência do modelo moderno liberal-burguês de pensamento acerca do homem e, por conseguinte, do Direito. Fatos que viriam cobrar a necessidade de uma nova idéia e um novo modus do Direito perceber o humano ${ }^{3}$.

Três vias devem ser mencionadas para uma bem conseguida explicitação dessa questão. Em primeiro, há uma alteração de ordem filosófica, em que, o pensamento moderno pretende ser superado. Essa pretensão ruma no sentido de evidenciar o fim das metafísicas essencialistas a anunciar o fim dos fundamentos estanques. Com esse intuito, o pensamento filosófico deixa para trás um paradigma consciencial em que a essência das coisas estaria guardada na consciência de si do pensamento pensante. Superação que foi anunciada com o esbatido linguist turn, que, mormente, é explicado como o paradigma que prescreve a existência do homem na linguagem e que apenas por ela e nela mesma vem à epifania.

A questão da temporalidade é outro mote que influencia deveras essa mudança radical de pensamento. Conceitos como o de historicidade radical fulminam as bases essencialistas que revestiam sobremaneira o ideário anterior. A questão do homem se dá no tempo e é nele, portanto, que o mesmo se resolve. A existência sem fundamento do homem é constituída pela sua colocação no tempo, pela sua indeterminação e capacidade de "ser para o futuro que é". Ente que ao se interrogar pelo Ser transcende o seu existir mesmo criando o novo. Dessa forma, a assumir sua capacidade de ser novador.

O estabelecimento destas questões deu ao homem a capacidade de transmutar-se da condição de "pastor de seu Ser" e isto fora decisivo, pois, ao se constituir distante das metafísicas que o aniquilavam, o homem se descobre como ser frágil que precisa do outro para compor sua existência. Destrona-se aqui o sujeito racional da modernidade. ${ }^{4}$

\footnotetext{
${ }^{3}$ As indicações referidas neste parágrafo introdutório funcionam como pontos de referência, espécies de "fraturas epocais" sob as quais o ocidente veio a se erguer e formar os valores que por conseguinte estabeleceram uma nova forma de compreensão do humano que recobrou do direito uma visada diferente e uma forma outra de estribar as soluções aos problemas agora propostos. Nesse sentido, é evidente a queda do paradigma jurídico que possuía o cidadão-homem-proprietário a ser "protegido" por normas que não atentavam para o humano considerado ontologicamente enquanto tal.

${ }^{4} \mathrm{O}$ paradigma filosófico que estamos a informar é aquele que caminha em conjunto com as alterações do mundo jurídico, por essa, via percebemos que não há mais possibilidade de pensar o homem a partir de categorias prédadas, seja por uma essência teológico-metafísica, dominante do pensamento medieval, seja da opressão
} 
O homem deixa de ser uma categoria abstrata e distante da existência real. A metafísica moderna não conseguira captar o homem em sua existência verdadeira, que inclui, além da razão, a emoção, a desilusão e, sem dúvida, a dês-razão. Características que não compunham o "sujeito perfeito" da modernidade, composto pela liberdade e igualdade formal que o entendimento liberal permitia.

\begin{abstract}
O esgotamento das pretensões totalizantes de uma razão única tomou várias formas, que são todas indicações para escolhas, valores, juízos. O sábio, que era para Aristóteles aquele que sabe os princípios primeiros, não se transformou simplesmente num cético indiferente, para quem tudo é igualmente verdadeiro e falso a um só tempo. A capacidade de viver numa racionalidade plural é coisa bem diferente, e disso só temos por enquanto uma vaga idéia. Mas sabemos pelo menos que o sábio pósmoderno deveria ser alguém que percorreu uma longa estrada para deixar atrás de si o mito da verdade última e definitiva - a um só tempo tranqüilizador e ameaçador, como um pai severo e protetor - ,descobrindo em contrapartida o valor do amor. (VATTIMO, in, LE NOUVEL OBSERVATEUR (org.), (1999, p. 62).
\end{abstract}

A outra alteração trazida pelo pensamento que se quer pós moderno diz respeito à questão político-jurídica que surge com o advento do segundo pós-guerra, com a crise do positivismo que teve como corifeu o jurista Hans Kelsen. As atrocidades cometidas na guerra em questão trouxeram à pauta do dia tentativas de reabilitação de um pensamento acerca do direito natural. Tese que não conseguiu ressonância por ainda se manter presa a um ideário ahistórico e absolutizante, o que não condizia com o pensamento contemporâneo. Essa tentativa acabou por se não mostrar frutífera, apesar de receber aderências de juristas de monta, tais como, Gustav Radbruch, pois, como diria Castanheira Neves a face extremamente versátil e disforme dos vários reclames de direito natural acabaram por mostrá-la uma alternativa inviável para o momento.

Ainda nesse contexto, presenciamos a libertação político-ideológica de vários Estados europeus de regimes totalitaristas e o fervor democrático não tardou a tomar conta do pensamento jurídico e político. As democracias nascentes receberam constituições programáticas que previam então a necessidade de realização, preservação e quase idealização de direitos fundamentais ditos inalienáveis. Restava agora a adequação dos ordenamentos

raciomalizante que fundamenta a modernidade, a existência no tempo e na linguagem, categorias expostas nitidamente no pensamento de Heidegger e também precisamente de Nietzsche, destronam essas racionalidades estabelecidas a priori e evidenciam a necessidade temporal que é o homem. Reconhecer-se no tempo é reconhecer o limite de uma razão abstrata e que oferece a percepção do homem enquanto construção e não como dado. Essa mudança de perspectiva fulmina as categorias jurídicas estanques e permite a construção de novos personagens na cena jurídica. Podemos colher grandes ensinamentos acerca em: CASTANHEIRA NEVES, Antônio. A crise actual da filosofia do direito no contexto da crise global da filosofia - Tópicos para a possibilidade de uma reflexiva reabilitação, Boletim da faculdade de Direito da Universidade de Coimbra, Coimbra Editora, 2003. 
jurídicos de bases liberais ao novo programa que o pensamento contemporâneo agora viria a anunciar.

Portanto, as transformações filosóficas e políticas desembocariam evidentemente no pensamento jurídico transformando as bases de sua existência e aplicação. O homem agora não mais se alia a uma categoria metafísica para justificar sua existência. Os valores historicamente constituídos pelo homem ocidental é que caracterizam sua história e se, percebemo-nos como seres históricos, nossa existência, agora entregue em nossas mãos, precisa ser cuidadosa. O pensamento político vem agora regido por uma Constituição que ganha estatuto normativo, prescreve programas, além de guardar direitos fundamentais á existência desse novo homem que aparece. A realização do homem é o cerne do pensamento jurídico contemporâneo. A Declaração de 1948 é referencial nesse sentido e as Constituições posteriores a ela não poderiam dela se distanciar.

De Estado Liberal e ausente da vida do cidadão, o Estado, agora regido pela Constituição, necessita realizar seus preceitos, e as democracias constitucionais agora se preocupam com o homem real. O Estado não apenas garante, mas promove o homem e fornece condições para tanto. O Estado Social Democrático de Direito nasce com o condão de realização da dignidade da pessoa humana, valor esquecido durante e que agora figura como centro e alicerce do ordenamento jurídico.

Esse quadrante influenciaria deveras a forma como direito seria aplicado a partir de então. Assim, o presente texto quer abordar a mudança de perspectiva entre um paradigma liberal, que cultuava a propriedade como mote fundador e fundamentador das relações de direito, as quais, eram regidas pelo Código Civil - nesse momento, o documento jurídico que regulava de fato as relações entre os homens - e o nascimento de um novo paradigma que muda o protagonista da cena. O pensamento que supera esse paradigma moderno e diríamos, positivista do direito, alça a pessoa para o patamar central do palco das realizações jurídicas, e a propriedade, tema alvo das peças outrora encenadas, passa a coadjuvante sob os auspícios do direito pós-moderno.

Um escorço mostrará a necessidade de passagem de um paradigma de Estado Liberal para o florescimento dos Estados Sociais Democráticos de Direito e as nuanças que essa alteração estabelece ao direito a partir da idéia de realização dos valores constitucionais enquanto valores jurídicos e não mais como meros guias políticos.

A mudança do paradigma estatal está intimamente relacionada ao nascimento da perspectiva neoconstitucionalista do Direito. A ascensão das democracias constitucionais, primeiro na Europa e um pouco mais tardiamente na América Latina, trouxe nova roupagem à 
realização do Direito. O século XX brindava a interpretação constitucional do Direito e precisava, ao mesmo tempo, encontrar uma forma de solucionar os entraves que nasceriam sempre quando um paradigma está em crise prestes a ser substituído.

O Direito Civil, que imperou durante o pensamento moderno e patrimonialista, sentia seus alicerces serem contestados pelo novo paradigma que se estava a erguer. Contudo, ao invés de levantar armas contra a premente constitucionalização das interpretações jurídicas, o Direito Civil se alia às vestes constitucionais do ordenamento. Essa ação resultou no que agora chamamos Direito Civil Constitucional.

Diversas foram as conseqüências da relação entre o Direito Civil e o Direito Constitucional. No entanto, o caminho de nossas atenções neste trabalho, pautar-se-á em anunciar como esses influxos neoconstitucionalistas influenciaram e estão a influenciar o instituto da responsabilidade civil, sendo este o recorte feito para aclararmos algo maior, qual seja, a chamada constitucionalização do direito civil.

\section{CONSTITUCIONALIZAÇÃO DO DIREITO CIVIL}

Falar em constitucionalização do direito civil significa colocar em debate uma mudança de paradigma há muito reclamada pelos juristas. Depois de muito tempo, o Código Civil, tido por muitos como a Constituição do homem comum, sai do centro das relações jurídicas privadas, deixando a Constituição Federal assumir o seu lugar. Significa que o centro deixa de ser o patrimônio para dar lugar à valorização e dignidade da pessoa humana.

Os autores Gagliano e Pamplona Filho (2005) fazem uma retrospectiva ao Código Civil de 1916 ressaltando suas características como instituto patrimonialista, egoísta e autoritário, baseado nos conceitos valorados da sociedade daquela época. A análise permite ver como a constituição deixou de ser uma mera carta política para assumir o papel de corpo normativo superior, a qual todas as demais normas devem se submeter.

Com a mudança da sociedade e a instauração do Estado Democrático de Direito, os valores patrimoniais e individualistas foram ultrapassados e o Código Civil precisou se adequar a tal concepção de colocar a pessoa em prioridade e não o que ela possui, em se preocupar com o "ser" e não com o "ter".

No contexto do capitalismo absoluto, o burguês proprietário era visto como o único sujeito de direitos e ainda que fosse garantida a igualdade, esta se mostrava impossível na prática visto que os menos favorecidos não encontravam meios de fazer valer qualquer direito. Nas palavras de Sarmento (2010, p. 69), “A ordem jurídica cerrava seus olhos para a 
desigualdade de fato, que dominava o espaço privado, e com a sua aparente neutralidade, chancelava a opressão".

Desde então, fez-se extremamente necessário uma mudança na forma de pensamento que acabou por culminar neste processo de constitucionalização, em que os institutos do direito privado precisarão ser redefinidos ou elaborado sob a égide das garantias estabelecidas constitucionalmente.

Nesse mesmo sentido é que Sarmento (2010) explica que no Brasil existem muitas normas editadas em outro contexto social e axiológico e que se chocarão freqüentemente com a Constituição Federal, exigindo dos juristas uma aplicação consoante com os valores constitucionais estabelecidos independente do choque ser expresso ou não. Além disso, segundo ele, a Constituição deve funcionar também como limite à possíveis retrocessos na legislação privada que se tornam arriscados nesse período de crise do Estado Social.

Como muito bem dissertado por Lôbo (2003), com todas as mudanças, embora alguns traços dos valores antigos ainda persistam na nossa legislação civilista, o indivíduo proprietário sai de cena para que a pessoa humana possa atuar, e a partir disso a família deve se fundar na afetividade, a propriedade deve ter como conteúdo e limite a função social, e o contrato deve ser considerado na sua desigualdade material dando proteção ao contratante mais fraco. Segundo ele, quando a norma anterior é incompatível com a Constituição deve ser revogada ${ }^{5}$ e a posterior, deve se entender como inconstitucional, pois é o Código Civil que precisa ser lido à luz da Carta Magna e não o contrário.

O debate sobre a constitucionalização do Direito Civil também implica mencionar a questão da aplicação dos Direitos Fundamentais (previstos por excelência no texto constitucional) no âmbito das relações privadas. De fato, o movimento da constitucionalização do Direito Civil levou ao reconhecimento da eficácia horizontal dos direitos fundamentais. Afirma-se assim que os direitos fundamentais não são oponíveis apenas ao Estado, conforme a concepção clássica advinda dos valores da Revolução Francesa (eficácia vertical), mas também podem ser invocados nas relações privadas.

Sobre o tema, com eloqüência singular, Farias e Rosenvald (2009, p.43) ensinam que:

\footnotetext{
5 Tecnicamente, a norma editada anteriormente a uma nova ordem constitucional não é revogada pela mesma. Sobre tal norma, é dito que não foi recepcionada pela ordem constitucional vigente. Contudo, tal classificação não retira formalmente a norma do mundo do direito positivo, embora seja permitido ao operador do direito não aplicála no caso concreto, dada a sua incompatibilidade com a Constituição. Para que a mencionada norma seja excluída do ordenamento positivo, necessita ser revogada, o que só ocorrerá por força de nova lei tratando do mesmo assunto.
} 


\begin{abstract}
A título exemplificativo, é possível afirmar que a exclusão da pessoa jurídica de um associado que pratica condutas inconvenientes e prejudiciais à associação como um todo, assim como a aplicação de multa ao condômino antisocial (que é aquele que incomoda a paz coletiva do condomínio, gerando incompatibilidade de convivência), consentidas pelos arts. 57 e 1.337 do Código Civil, respectivamente, têm de ser precedidas de ampla defesa e contraditório (o devido processo legal), garantido pelo art. $5^{\circ}, \mathrm{LV}$, da Lex Legum, sob pena de serem afrontados os direitos fundamentais consagrados constitucionalmente.
\end{abstract}

Como se vê, em um Direito Civil constitucionalizado, os direitos fundamentais também são princípios basilares das relações privadas, devendo ser respeitados não apenas pelo Poder Público, que tem a obrigação de geri-los e garanti-los aos cidadãos, mas também devem ser observados pelos particulares, vistos que todos vivem sob a égide da mesma Constituição.

Segundo o renomado doutrinador César Fiúza (2009), o Código Civil ainda é o centro do direito privado enquanto que a constituição é o centro do ordenamento jurídico como um todo.

Para um melhor entendimento acerca de como deve ser a leitura constitucional do Código Civil usar-se-á como exemplo uma das belíssimas obras do dramaturgo William Shakespeare (2007), O Mercador de Veneza ${ }^{6}$. Nesta obra, Antônio figura como o mercador protagonista, que para ajudar um amigo a se casar com Pórcia, realiza um empréstimo com o judeu Shylock. Entretanto, Shylock aproveitou a oportunidade para estabelecer uma cláusula contratual determinando que no caso de inadimplência no pagamento, teria direito a retirar do corpo de Antônio, seu inimigo, uma libra de carne, de forma que este morreria. Antônio celebra o contrato e não consegue efetuar o pagamento. Shylock obtém judicialmente o direito de retirar a libra de carne, porém como a defesa alegou e o julgador acatou, para executá-lo não poderia retirar nenhuma gota de sangue de Antônio. Daí, embora tenha reconhecido o seu direito, Shylock se vê impossibilitado de satisfazer sua pretensão.

Trata-se de um contrato de empréstimo que traz a cláusula que concede ao contratante Shylock o poder de retirar do corpo do outro contratante Antônio uma libra de carne caso este não efetuasse o pagamento. Em outras palavras, uma cláusula que autoriza a morte de um dos contratantes pelo outro em caso de inadimplência pode ser considerada como válida?

Estabelece-se abaixo um paralelo seguindo a explicação detalhada feita por Fiúza (2009) sobre um exemplo semelhante: antigamente, quando não se falava em direito civil constitucional, a resposta seria não porque segundo o art. 104, II do Código o objeto do contrato precisa ser lícito, o que não ocorre. Radicalizando o movimento da constitucionalização, a

\footnotetext{
${ }^{6}$ Brilhante obra do poeta e dramaturgo William Shakespeare trazendo para o romance central vários questionamentos no campo social e jurídico de uma época onde o comércio, a burguesia, e a disputa entre cristãos e judeus dominavam a cidade de Veneza. A obra fez um grande sucesso no teatro, na literatura e no cinema e constantemente vem sendo estudada.
} 
resposta seria não porque viola o princípio da dignidade da pessoa humana, consagrado no art. $1^{\circ}$ da Constituição Federal. Entretanto, a resposta reputada correta pelo autor seria que não é válida a cláusula porque o objeto é ilícito, uma vez que afronta o princípio da dignidade da pessoa humana. Esta sim seria uma verdadeira leitura do caso sob a ótica do Direito Civil constitucionalizado ou constitucional.

Fiúza (2009) também ressalta a importância de não se radicalizar o fenômeno da constitucionalização, pois se mal aplicado, os novos valores de dignidade, interesse público ou função social podem suprimir outros como a liberdade.

\section{REFLEXOS NA RESPONSABILIDADE CIVIL}

Depois de entendida a importância da Constitucionalização do Direito Civil, destinar-seá a compreender seus reflexos na Responsabilidade Civil, que no momento é o ponto central desse estudo.

Vive-se atualmente em uma sociedade onde o risco e a incerteza estão cada vez mais presentes, colocando por terra a noção de segurança jurídica. Entretanto, a necessidade de se tutelar a dignidade da pessoa humana é uma verdade absoluta e indiscutível. Tal princípio constitucional determina uma grande alteração no instituto da Responsabilidade Civil que agora não busca apenas a punição do responsável pelo dano, mas também a proteção da vítima.

A Responsabilidade Civil se apresenta de forma flexível e, ao contrário do Direito Penal, não traz tipificado as formas de dano e de responsabilização, mas sim prevê em cláusulas gerais com conceitos abertos e indeterminados, deixando na maioria das vezes a critério do julgador identificar, segundo a consciência social, o que deve ou não ser indenizado.

O problema está na inexistência de critérios para se determinar o dano que merece tutela jurídica, chegando ao ponto de aumentar assustadoramente as inúmeras formas de danos ressarcíveis, em especial no que tange às hipóteses de dano extrapatrimonial, nos quais o fundamento maior é o sofrimento da vítima. Houve um aumento significativo dos pedidos e concessões de indenizações por dano moral nos últimos tempos, tanto que hoje, justificavelmente, se usa muito a expressão “indústria do dano moral”.

Deve-se considerar que sempre que tratamos de relações humanas, o sofrimento e a tristeza são elementos possivelmente presentes, não podendo ser estes os únicos fundamentos para se definir dano moral. A ausência de uma definição plausível e objetiva dessa espécie de dano tem contribuído muito para acentuar o risco, violando também o princípio de tutela dos direitos fundamentais da pessoa humana. 
Uma das melhores soluções imediatas para se resolver os problemas encontrados neste ramo do direito é encontrada na Constituição. Para Maria Celina Bodin de Moraes: "O critério mais consistente sustenta que indenizável será o evento danoso relevante segundo uma ponderação de interesses em jogo à luz dos princípios constitucionais”. E ainda:

\footnotetext{
De maneira geral, a inspiração constitucional fez com que os princípios normalmente alheios ao surgimento da obrigação de indenizar fossem incorporados ao definir o regime de reparação civil. Se a responsabilidade civil tradicional se baseava exclusivamente na tutela do direito de propriedade e dos demais direitos subjetivos patrimoniais, hoje a dignidade da pessoa humana, a solidariedade social e a justiça distributiva influenciam profundamente toda a sistemática do dever de ressarcir. (MORAES, 2007, p.445)
}

A influência dessa nova percepção da Responsabilidade Civil segundo valores constitucionalmente estabelecidos podem ser notados, por exemplo, em dois aspectos:

O primeiro é a possibilidade de se indenizar apenas por dano moral conforme art. $5^{\circ}, \mathrm{V}$ e $\mathrm{X}$ da $\mathrm{CF} / 88$ considerando dano moral como toda conduta atentadora à dignidade da pessoa humana sujeita de direitos e levando em consideração também outros princípios como o da igualdade, onde se percebe, por exemplo, no fato de se indenizar por ofensa à integridade psicofísica de uma criança e não se indenizar a dissolução de uma relação conjugal onde se verifica a igualdade entre os cônjuges e a liberdade de cada um deles.

O segundo ponto de interferência constitucional é em relação à responsabilidade objetiva, que dispensa a análise do elemento subjetivo para que o agente tenha a obrigação de indenizar, ou seja, a responsabilidade de reparar o dano independe de culpa. Considerando o aumento de danos causados e a dificuldade da vítima de se provar o elemento da culpa criou-se a possibilidade de reparação objetiva conforme previsão dos artigos 37, §6 e 21, XXIII,"c" da Constituição, além de outras normas estabelecidas no Código de Defesa do Consumidor ou mesmo no Código Civil. Aqui se revela o solidarismo constitucional, preocupado em proteger o lesado, tendo que definir apenas se ele tem ou não direito de ser indenizado.

\section{CONCLUSÃO}

O instituto da Responsabilidade Civil se mostrou hábil ponto de referência para aclarar os efeitos da constitucionalização do edifício jurídico a que se liga, qual seja, o direito civil. Historicamente isso já se mostra uma evidência e os efeitos jurídicos da transformação filosófico-política não poderiam ser negados. 
Quando a pessoa deixa de ser percebida enquanto instância abstrata e os valores são retirados de uma instância meramente formal, exsurge as novas possibilidades de ressarcimento que o pensamento jurídico contemporâneo vê abrigados dentro das Constituições dos Estados democráticos.

Nesse sentido, pudemos perceber que o pensamento jurídico alicerçado pelas constituições contemporâneas, fora o fiat lux que impulsionara essa nova forma de aplicação do direito civil e uma sua melhor realização em face dos problemas sócio-jurídicos atuais.

Aliar o pensamento filosófico-jurídico que sofrera profundas transformações a partir do segundo após-guerra com a dogmática de realização do direito civil conseguido por intermédio de um "filtro constitucional" é o elo que traz à tona o instituto em análise no sentido de evidenciar, a partir deste, os reflexos constitucionais dentro da hermenêutica de realização do direito civil nos dias atuais.

Assim, quisemos mostrar que a idéia de "repersonalização do direito civil" está exemplificada a partir do olhar mais cuidadoso dado para o dano moral, pela teoria da socialização do risco a "evolução" da responsabilidade subjetiva à responsabilidade objetiva, afirmando o privilégio da pessoa, e a maneira mais humanitária e menos monetária dentro da qual parece caminhar o direito civil nos dias atuais.

É evidente que esse novo momento da responsabilização civil não se encontra encerrada com as questões tratadas, muitos outros problemas estão por vir, e outros ainda restam por resolver. Assim, é inegável que esse novo caminhar da responsabilidade civil difundiu a existência de direitos ligados à relação obrigacional em uma amplitude jamais vista, o que trouxe avanços significativos à ciência civilística em prol do cidadão. No entanto, a experiência jurídica brasileira ainda precisa definir vários nortes, conceitos, parâmetros disciplinadores e detalhes maiores a fim de que se promova a solidificação dos verdadeiros fundamentos e objetivos da responsabilidade civil.

Muito se teme a respeito da posição da responsabilidade civil no ordenamento atual, posto que o quantitativo numérico das ações de reparação de dano cresceu fortemente nos últimos anos, muitas vezes, refletindo demandas de forma desvirtuada da real finalidade do instituto. Em muitos casos, principalmente no que tange ao dano moral, o objetivo é mais mercantil e pecuniário do que o ressarcimento do prejuízo causado. Por isso, surge a necessidade do próprio direito - doutrina e jurisprudência - estabelecer contornos ao seu limite, sob pena de padecer do mal da banalização. 
BRASIL. Código Civil. Lei número 10.406, de 10 de Janeiro de 2002.

BRASIL. Constituição da República Federativa do Brasil de 1988. São Paulo. Saraiva, 2004.

CASTANHEIRA NEVES, Antônio. A crise actual da filosofia do direito no contexto da crise global da filosofia - Tópicos para a possibilidade de uma reflexiva reabilitação. Boletim da faculdade de Direito da Universidade de Coimbra. Coimbra Editora. 2003.

FARIAS, Cristiano Chaves de; ROSENVALD, Nelson. Direito Civil Teria Geral. 8. ed. Rio de Janeiro; Lumen Juris. 2009, p. 43.

FIUZA César. Direito Civil Curso Completo. 13. ed. Belo Horizonte; Del Rey. 2009.

GAGLiAnO, Pablo Stolze, FILHO, Rodolfo Pamplona. Novo Curso de Directo Civil. Volume I. 6. ed. São Paulo. Saraiva. 2005.

LE NOUVEL OBSERVATEUR (org.) Café Philo: As grandes indagações da filosofia. Rio de Janeiro. Zahar, 1999.

LÔBO, Paulo Luiz Neto. Constitucionalização do Direito Civil. In FIUZA, César et. al. (coord). Direito Civil - Atualidades. Belo Horizonte. Del Rey. 2003.

MORAES, Maria Celina Bodim. A Constitucionalização do Direito - Fundamentos Teóricos e Aplicações Específicas. In SOUZA, Cláudio Pereira de Neto; SARMENTO, Daniel (coord). Rio de Janeiro. Lumen Juris. 2007

SARMENTO, Daniel. Direitos Fundamentais e Relações Privadas. 2. ed. Rio de Janeiro. Lumen Juris. 2010.

SHAKESPEARE, William. O Marcador de Veneza. São Paulo; Martin Claret. 2007. 